\title{
Comparision of Packed Cell Volume by Manual and Automated Methods
}

\author{
Dhayanithi J' and M P Brundha ${ }^{1 *}$ \\ ${ }^{1}$ Saveetha Dental College and Hospitals, Saveetha Institute of Medical and \\ Technical Sciences, Saveetha University, Chennai, Tamilnadu, India, 600077 \\ ${ }^{1}$ Associate Professor, Department of Pathology, Saveetha Dental College and Hospitals, \\ Saveetha Institute of Medical and Technical Sciences, Saveetha University,Chennai, \\ Tamilnadu,India, 600077
}

\section{ABSTRACT}

The Packed cell volume [PCV] is a measurement of the proportion of blood that is made up of cells. The Packed cell volume [PCV] can be determined by centrifuging heparinized blood in a capillary tube at 10,000 RPM for a few minutes. This separates the blood into the layer. The automated hematology analyzer uses the principle in which the blood is passed between two electrodes through an aperture so narrow that only one cell can pass through at a time. The measurement depends on the number and size of the red blood cell.Hematocrit levels that are high or low indicate a blood disorder. PCV valve is normally $42 \%$ to 50\% for men and 36\% to $45 \%$ for women. The aim of our study is to compare the PCV value by manual and automated method. This study is a prospective study, by comparing the packed cell volume by the manual and the automated method using twenty peripheral venous blood samples, which were collected from the patient with an informed consent. It is evident that measuring the packed cell volume by the automated method was found to be more accurate when compared to the manual method.This study depicts a significant outcome in measuring the packed cell volume by the automated method could be more effective in obtaining accurate interpretation.

KEY WORDS: PACKED CELL VOLUME, MANUAL, AUTOMATED, HEMATOCRIT, RBCS.

\section{INTRODUCTION}

The packed cell volume (PCV) is a concentration of the Red blood cells in the given volume of the blood. There are other names for the packed cell volume (PCV) such as Hematocrit (Hct), the volume of packed red cells (VPRC), or erythrocyte volume fraction (EVF). The value is expressed as a percentage or fraction of cells in the

\section{ARTICLE INFORMATION}

${ }^{*}$ Corresponding Author: brundha.sdc@saveetha.com Received 9th June 2020 Accepted after revision 8th August 2020 Print ISSN: 0974-6455 Online ISSN: 2321-4007 CODEN: BBRCBA

Thomson Reuters ISI Web of Science Clarivate Analytics USA and Crossref Indexed Journal

\section{Clarivate Analytics}

\section{rrossef}

NAAS Journal Score 2020 (4.31) SJIF: 2020 (7.728)

A Society of Science and Nature Publication,

Bhopal India 2020. All rights reserved.

Online Contents Available at: http//www.bbrc.in/

Doi: http://dx.doi.org/10.21786/bbrc/13.7/2 blood. The packed cell volume (PCV) can be determined by centrifuging di-potassium EDTA anticoagulated blood in a capillary tube or Wintrobe's tube at 10,000- 12000 RPM for 30 minutes. This separates the blood into layers. The top most layer was the plasma, which was separated by a column of buffy coat from the packed red blood cells. The buffy coat is composed of white blood cells and platelets. The upper limit of the Red cell column was taken as PCV value in percentage. The measurement depends on the number and size of the red blood cell. PCV valve is normally $42 \%$ to $50 \%$ for men and $36 \%$ to $45 \%$ for women. It is a part of a person's complete blood count results along with hemoglobin concentration, white blood cell count and platelet count(Wennecke, 2004). 
Hematocrit levels that are too high or too low can indicate a blood disorder, in cases of dengue fever, a high hematocrit is a danger sign of an increased risk of dengue shock syndrome(Morens, Halstead and Repik, 1985). Polycythaemia Vera, a Myeloproliferative disorder, Hypoxic state, reduced oxygen saturation of the red cells, individuals living in high altitudes have an increased PCV value. In these conditions, the RBC count and the concentration were increased, which in turn increased the PCV valve(Fairbanks, 1999).

In the case of low red blood cell count leads to Pregnancy women having additional fluid in the blood. This could potentially lead to a small drop in haematocrit levels(Kawthalkar, 2010). Haematocrit can vary from the determining factors of the number of red blood cells. These factors can be from the age and sex of the subject(Kertész and Hlubik, 2002). A higher packed cell volume level signifies the blood sample's ability to transport oxygen in case of hypoxia. The optimum PCV levels have been studied through combinations of assays on the given blood samples itself along with viscosity and hemoglobin level(Geetha, 2017). With modern lab equipment, the packed red cell volume is calculated by an automated analyzer and is not directly measured(Rossman, 2011). The PCV is slightly more accurate as the PCV includes small amounts of blood plasma trapped between the red cells. An estimated packed red cell volume as a percentage may be derived by tripling the hemoglobin concentration in $\mathrm{g} / \mathrm{dl}$ and dropping the units(Bull and Brecher, 1974). A Wintrobe's tube is a narrow glass tube measuring $110 \mathrm{~mm}$ long and with the hole diameter $1 \mathrm{~mm}$ and graduation from 0 to $100 \mathrm{~mm}$ in both ascending and descending order. This method has been succeeded by the "micro-haematocrit" method which uses a small capillary tube instead of a Wintrobe's haematocrit tube(Don, 2003).

\section{MATERIAL AND METHODS}

This study is a prospective study, by comparing the Packed cell volume by the manual and the automatic method was assessed using twenty peripheral venous blood samples which were collected from the patients. The patient population was selected randomly from the clinical laboratory of Saveetha Dental College. The patients were examined, as a part of standard laboratory routine for hematological examinations, after informed consent was obtained by the patient or their responsible others. Approval was given by the ethical committee for research involving humans, Saveetha Institute of Medical and Technical Sciences. The criterion for the sample selection was the clinical request for Haemoglobin and complete blood count. No restriction was made for sex, age or clinic history of each patient under clinical care. All the procedures were carried out in the clinical laboratory of Saveetha Dental College, Saveetha Institute of Medical and Technical Sciences.

Wintrobe's method: The macrohematocrit method uses a Wintrobe hematocrit tube, a centrifuge machine, and a Pasteur pipette. Blood is filled in the Wintrobe hematocrit tube up to $100 \mathrm{~mm}$ mark with the help of Pasteur pipette. Care is taken not to leave any bubble in the blood column. For this, the tube is filled slowly with the tip of the pipette being always below the highest position of the blood column. Then, the tube gets placed in the centrifuge machine. When testing a single specimen, another blood-filled Wintrobe hematocrit tube is kept on the opposite holder to counterbalance. The spin setting is $3000 \mathrm{rpm}$ for $30 \mathrm{~min}$. After completion of the centrifugation, the tube is taken out, and RBC column height is reported as Hematocrit (HCT). During the reporting, special precaution is necessary to omit the buffy coat, which is a combination of WBC and platelets. This layer should not be included in the HCT, as it may lead to false-positive results.

Method and Principle of automated hematology analyzer: The procedure was done as per the manufacturer's instructions $\mathrm{m} 9$ mind ray. The Automated hematology Analyzer used the counter principle, which blood is passed between two electrodes through an aperture so narrow that only one cell can pass through at a time. The PCV was a calculated value that was obtained from the hemoglobin level. The calculation was inserted as data modification in the automated analyzer by the system management services as per the laboratory scope and methodology.

Statically analysis: Statistical analysis was accomplished by the application of unpaired t-tests using sigma plot platform version 12, statistical significance was considered for the manual and the automatic method is $\mathrm{p}<0.001$.

\section{RESULT AND DISCUSSION}

Table 1. unpaired $\mathrm{t}$ - Test for both male and female by manual and automated method for PCV value. When compared, the manual method shows higher PCV value than the automated method and the difference was statistically significant $(\mathrm{p}<0.001)$

\begin{tabular}{l|rrrrr}
\hline $\begin{array}{l}\text { Treatment } \\
\text { name }\end{array}$ & No:of samples & Missing & Mean & STD DEV & SEM \\
\hline Manual & 20 & 0 & 50.55 & 11.194 & 2.503 \\
\hline Automatic & 20 & 0 & 43.28 & 3.71 & 0.83 \\
\hline Difference & 20 & 0 & 7.27 & 9.078 & 2.03 \\
\hline
\end{tabular}

During the experiments, it was found that the automated method demanded special precautions such as avoiding bubbles when agitating the sample in the reagent bottle, incubating sample-stain diluent suspensions at room temperature, and protecting the sample from exposure to light. It should be emphasized that these precautions are not to be found in the manufacturer's manual. For this work, the reaction occurred after 15-minute incubation and approximately 1 minute for each measurement. The whole process was performed for over 2 hours. Despite the great number of samples processed, we were able to both meet the time limit of the standard determination 
and to prevent errors, even if the suspension presented stability, as informed by the manufacturer.

Table 2. Unpaired $\mathrm{t}$ - Test only for male by manual and automated method for PCV value.The average PCV valve of males in this study, for Manual is 57.5\% and the automated method is $45.36 \%$ with a difference of $12.14 \%$ which also showed a significant difference of $\mathrm{p}<0.001$. From this, there is a significant difference between manual and automated methods

\begin{tabular}{|c|c|c|c|c|c|c|}
\hline $\begin{array}{l}\text { Treatment } \\
\text { name }\end{array}$ & No:of samples & Missing & Mean & & STD DEV & SEM \\
\hline Manual & 10 & & 0 & 57.5 & 10.102 & 3.195 \\
\hline Automatic & 10 & & 0 & 45.36 & 3,396 & 1.074 \\
\hline Difference & 10 & 0 & 0 & 12.14 & 7,324 & 2.316 \\
\hline
\end{tabular}

Table 3. unpaired $t$ - Test only for female by manual and automated method for PCV value.The average PCV valve for Manual is $50.55 \%$ and the automated method is $43.28 \%$ with a difference of $7.27 \%$. The statistical analysis showed a significant difference of $p>0.001$. Hence we found. In females, there is no significant difference between the manual and automated method of PCV values

\begin{tabular}{l|cccccc}
\hline $\begin{array}{l}\text { Treatment } \\
\text { name }\end{array}$ & No:0f samples & Missing & Mean & & STD DEV & SEM \\
\hline Manual & 10 & 0 & 43.6 & 7.427 & 2.349 \\
\hline Automatic & 10 & 0 & 41.2 & 2.811 & 0.889 \\
\hline Difference & 10 & 0 & 2.4 & 8.224 & 2.601 \\
\hline
\end{tabular}

Table 4. ANONA with linear regression analysis for $\mathrm{P}$ and $\mathrm{R}$ value. SS- Sum of square, MS- Mean square. Linear regression analysis also showed that there is a significant difference between the manual and automated PCV calculation methods with a p-value of less than 0.001 and showed systematic errors and Random error of $0.64 \%$ in the manual method, which is higher than the automated method

\begin{tabular}{|l|c|c|c|c|c|}
\hline & DF & SS & MS & F & P \\
\hline Regression & 1 & 1108.296 & 1108.296 & 15.675 & $<0.001$ \\
\hline Residual & 18 & 1272.654 & 70.703 & & \\
\hline Total & 19 & 2380.95 & 125.313 & & \\
\hline
\end{tabular}

Unpaired t-tests are done for packed cell volume by manual and automatic methods for all 20 samples from 10 males and 10 females (Table 1). The average PCV valve for Manual is 50.55\% and the automated method is $43.28 \%$ with a difference of $7.27 \%$. The statistical analysis showed a significant difference of $p<0.001$. From this there is a significant difference between manual and automated methods.
Unpaired t-tests are done for packed cell volume by manual and automatic methods only for samples from 10 males (Table 2). The average PCV valve for Manual is $57.5 \%$ and the automated method is $45.36 \%$ with a difference of $12.14 \%$ which also showed a significant difference of $p<0.001$. From this, there is a significant difference between manual and automated methods.

Unpaired t-tests are done for packed cell volume by manual and automatic method from the peripheral blood sample was collected only for ten females (Table 3). The average PCV valve for Manual is 50.55\% and the automated method is $43.28 \%$ with a difference of $7.27 \%$. The statistical analysis showed a significant difference of $p>0.001$. From this, there is no significant difference between manual and automated methods.

ANOVA with linear regression analysis was done in the data retrieved from the results. This is shown in Table 4. ANOVA with linear regression analysis also showed that there is a significant difference between the manual and automated PCV calculation methods with a p-value of less than 0.001 and showed systematic errors and Random error of $0.64 \%$ in the manual method, which is higher than the automated method. The scattered plot of the data (Figure 1) showed the distribution of the PCV values of all the 20 samples which were not distributed around the mean.

Figure 1: Scattered plot of Data showed the distribution of the PCV values of all the 20 samples which were not distributed around the mean

2D Graph 1

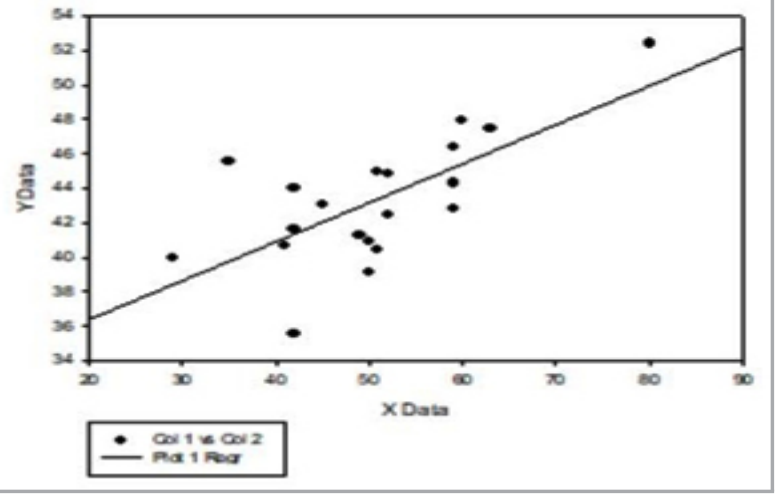

The study conducted by Ike S.O et al in 2010 (Ike et al., 2010)used the same methodology followed in our study with all the blood parameters by manual and automated methods of hematology. It showed that there was a significant difference between the manual and automated method of hematology analysis with a p-value of $<0.05$ and an error of $R=0.91 \%$. The study concluded that automated values were more reliable than the manual method. By comparing our study, the error was $R=0.64 \%$ for the PCV valve and similarly, our study also showed a significant difference between the two methods with lower error with automated value. 
Kakel et al in 2013(Kakel, 2013) was done a comparison of manual and automated hematology for all the parameters. It showed a significant difference between the manual and automated method of hematology analysis with PCV value of 53\% and 45\% for automated and manual method respectively. The study concludes that the automated PCV value is more than the manual method. By comparing our study, with the PCV value of 43.3\% and 52.3\% for an automated and manual method for PCV value. This showed a difference in the PCV value from the value of Kakel's study.

Karem et al(Karem, Sabour and Kulaifa, 2016) performed a comparison of manual and automated hematology for all the parameters. It showed that there was a significant difference between the manual and automated methods of hematology analysis with a p-value of $<0.001$. The study concludes that the automated PCV value is more than a manual method. By comparing our study, with the Significant difference between the Manual and automated method of Haematology analysis with a p-value of < 0.001. Zandecki M et al(Zandecki et al., 2007) did a comparison of manual and automated hematology for all the parameters. It showed that there was a significant difference between the manual and automated methods of hematology analysis with a p-value of $<0.001$. The study concludes that the automated PCV value is more than the manual method. Both the studies were showing that the automated value was higher than the manual method value in case of Packed cell volume. In our study we found in inverse that the manual method value was higher than the automated method value.

\section{CONCLUSION}

With the limitations of the study we conclude that the PCV value in the manual method is higher than the automated method and it is showing a significant difference in males than females. The present study depicts a significant outcome in measuring the packed cell volume by the automated method could be more effective in obtaining accurate interpretation.

\section{ACKNOWLEDGEMENTS}

The authors are thankful to Saveetha Dental college for providing a platform to express our knowledge.

Conflict of Interest: There is no conflict of interest declared by the authors.

\section{REFERENCES}

Bull, B. S. and Brecher, G. (1974) 'An evaluation of the relative merits of the Wintrobe and Westergren sedimentation methods, including hematocrit correction', American journal of clinical pathology. academic.oup. com, 62(4), pp. 502-510.

Don, M. (2003) 'The Coulter Principle: Foundation of an Industry', JALA: Journal of the Association for
Laboratory Automation. SAGE Publications Inc, 8(6), pp. 72-81.

Fairbanks, V. F. (1999) 'Polycythemia Vera: The Packed Cell Volume and The Curious Logic of The Red Cell Mass', Hematology, pp. 381-395. doi: 10.1080/10245332.1999.11746463.

Geetha, N. (2017) 'Packed Cell Volume (PCV) or Hematocrit', Practical Physiology, pp. 29-29. doi: 10.5005/jp/books/12995_6.

Ike, S. O. et al. (2010) 'Comparison of haematological parameters determined by the Sysmex KX - 2IN automated haematology analyzer and the manual counts', BMC clinical pathology. Springer, 10, p. 3.

Kakel, S. J. (2013) 'The evaluation of traditional and automatic Coulter method in estimation of haematological parameters in adult rats', Beni-Suef University Journal of Basic and Applied Sciences. Elsevier, 2(1), pp. 31-35.

Karem, K. K., Sabour, A. N. and Kulaifa, B. M. (2016) 'Comparison between manual procedure and automated for determinant of WBCs and PCV in maternity and labor hospital in Karbala city', Journal of Contemporary Medical Sciences. jocms.org, 2(7), pp. 93-95.

Kawthalkar, S. (2010) 'Packed Cell Volume', Essentials of Clinical Pathology, pp. 188-188. doi: 10.5005/jp/ books/11417_19.

Kertész, V. and Hlubik, I. (2002) 'Plasma ALP activity and blood PCV value changes in chick fetuses due to exposure of the egg to different xenobiotics', Environmental pollution . Elsevier, 117(2), pp. 323327.

Morens, D. M., Halstead, S. B. and Repik, P. M. (1985) 'Simplified plaque reduction neutralization assay for dengue viruses by semimicro methods in BHK-21 cells: comparison of the BHK suspension test with standard ..., Journal of clinical. Am Soc Microbiol. Available at: https://jcm.asm.org/content/22/2/250.short.

Rossman, M. A. (2011) 'Automated Detection of Hematological Abnormalities through Classification of Flow Cytometric Data Patterns'. digitalcommons.fiu.edu (FIU Electronic Theses and Dissertations). doi: 10.25148/ etd.FI11041506.

Wennecke, G. (2004) 'Hematocrit-A review of different analytical methods', Radiometer Medical ApS. acutecaretesting.org. Available at: https:// acutecaretesting.org/-/media/acutecaretesting/files/pdf/ hematocrit--a-review-of-different-analytical-methods. pdf.

Zandecki, M. et al. (2007) 'Spurious counts and spurious results on haematology analysers: a review. Part II: white blood cells, red blood cells, haemoglobin, red cell indices and reticulocytes', International journal of laboratory hematology. Wiley Online Library, 29(1), pp. 21-41. 